\title{
Value co-creation and donation in non-profits: a social analysis through the service-dominant logic
}

\author{
Renata Klafke $^{1}$ (D) Marta C. V. de Oliveira ${ }^{1}$
}

Received: 9 April 2021 / Accepted: 9 February 2022 / Published online: 8 March 2022

(c) The Author(s), under exclusive licence to Springer Nature Switzerland AG 2022

\begin{abstract}
This research explores the value proposition of Brazilian non-profits (NPOs) to society, how donors and NPOs perceive value co-creation, and the elements required for value co-creation to occur in a donation context. This study includes case studies with managers and donors from three distinct non-profit organizations in the same sector. We conducted semi-structured interviews, report analysis, and direct observations. The interviews were recorded and typed up for content analysis using the MAXQDA software. The triangulation approach and multilevel data collection contributed to the research's reliability and validity. NPOs propose value through marketing strategies, primarily by humanizing "sales techniques". Donors perceive value co-creation as a beneficial collaborative result. Value co-creation is a way for non-profit organizations to achieve their missions of assisting patients or families in need. Although there is strong evidence of dialogue and transparency elements in the donor-NPO relationship, other factors, such as the individual's background or empathy, stood out more in this context. Academically, this study contributes to the literature by elucidating the phenomena under multiple actor interaction regimes. Furthermore, most studies on value co-creation focus on customer participation and interaction in private organizational processes (i.e., innovation or feedback), leaving gaps for determining and exploring alternative forms of value co-creation. This gap was filled in this study.
\end{abstract}

Keywords Value co-creation · Donation $\cdot$ Non-profits $\cdot$ Service-dominant logic

Renata Klafke

nena.klafke@gmail.com; Renata.klafke@farroupilha.ifrs.edu.br

Marta C. V. de Oliveira

martacvasconcelos@hotmail.com

1 Business Management Department, Universidade Federal do Paraná (UFPR) - Brazil, Rua Lothario Messner S/N, Curitiba, Brazil 


\section{Introduction}

Business management and fundraising differ in the third sector from any private organization. In the case of an NPO (non-profit organization) that provides health services to the community, the assisted patients and their families are the beneficiaries of the value co-creation process. These actors are frequently the focus of most studies. However, donors play a significant role in making this process a reality.

Value co-creation is at the heart of the service-dominant logic (SDL) foundations, together with multiple actors, consumption experiences, resources, and the outcomes from these experiences (Vargo and Lusch 2004; Osei-Frimpong and Owusu-Frimpong 2017). So that the process of co-creation can happen, in addition to interaction, there is a need for people to be interested in sharing skills and resources (Vargo and Lusch 2004).

NPO research is critical since they serve a population that governments frequently overlook (Avner 2016). Amid the COVID-19 crisis, non-profit organizations are more important than ever, especially for poor people or people in undeveloped countries. Many jobs have been lost as a result of the COVID-19 pandemic. According to IFG INSIGHT (2020), no country has escaped rising unemployment. In Australia, a developing country, the proportion of the workforce receiving unemployment benefits has increased from 6 to $12 \%$; in the United States, $18 \%$ of individuals were receiving unemployment benefits as of early May (less than $1 \%$ before the crisis). Thus, one must wonder how worse it must have been for countries that do not fulfill their fundamental needs.

Given the social challenges and budgetary limits that non-profit organizations face, understanding the phenomenon of value co-creation in these organizations may enhance cooperation and donation. In this way, donations are given through the interaction, collaboration, and involvement between the organization (NPO) and the donor.

The DART (Dialogue, Risk Management, Access, and Transparency) practices are the basis of any study of value co-creation (Prahalad and Ramaswamy 2004). According to the authors, these attributes should be presented in any value cocreation relationship. Therefore, these elements should be expected to be included in any value co-creation process. Nevertheless, is there anything else?

Considering the value co-creation perspective, i.e., the collaboration between a group of donors and NPOs, it seems that when actors co-create value through dialogue, access, transparency, and risk management (DART), individuals are more likely to donate.

By taking together the perspective of value co-creation and donation through the lens of the service-dominant logic, this research aims to explore the process of value co-creation in the third sector. Furthermore, this study emphasizes the interaction between actors (NPOs and donors) from the organization's perspective as both a value proposer and a beneficiary of the value co-created, which is another form of value co-creation. Here lies a contribution to the applied social science literature.

According to SDL, markets are more focused on relationships and collaboration than the competition (Vargo and Lusch 2016). Nonetheless, the importance 
of fundraising as a means of ensuring organizational survival is evident in a capitalist society. As a consequence, it is critical to understand: (i) how non-profits propose value to society in order to raise funds; (ii) how donors and non-profits perceive value co-creation; and (iii) the requirements for value co-creation to emerge in this donation context.

\section{Literature review}

\section{Values, value co-creation, and the service-dominant logic}

In sociology, values have always played a crucial role in motivating and guiding human action (Joas 2001; Thome 2015). According to seminal studies in this field, the value of anything originates from the group conception of desire and aspiration. However, it may also be specific to the individual according to the stimulus received and the environment in which we are enculturated (Kluckhohn 1951). In Business Management, value has been affected by economic (focused on monetary exchange) and sociological sciences (traditions, habits, and so forth). Until the 1990s, companies considered value to differentiate themselves and obtain a sustainable competitive advantage. Value was directly connected to the quality of a product, which generates revenue streams if approved by clients. The sound dominant logic is "regimented" this time.

The term value is value co-creation, a concept widely coined in the literature by Prahalad and Ramaswamy (2004). These authors revealed that the future of competition and market gain lies in the changes in the meaning of value. This change in the understanding of the concept indicates that organizations should be less concerned with the goods (products and services) themselves and pay attention to intangible resources, such as knowledge, information, and skills (Vargo et al. 2008).

When it comes to the process of value co-creation, Payne et al. (2008) say that it succeeds from "outside to inside" of the organization since value co-creation begins with a proposal. This proposal starts with the clients' understanding of "value", that is, organizations should direct their efforts to understand what is considered valuable for them. The value identification process and proposition will encompass mechanisms, activities, and interactions to support credit value (Payne et al. 2008). Nevertheless, the Business Management literature lacks evidence presenting how NPOs propose a value, contemplating this new service logic (SDL). The concept "value co-creation" was novel and obscure when Prahalad and Ramaswamy (2004) popularized it; therefore, the authors developed a model to explain it. This model, frequently cited in the literature, focuses on the features and actions during the value co-creation process. DART is categorized into four main components, as illustrated in Table 1.

The four fundamental DART elements must be present for the value co-creation process (Prahalad and Ramaswamy 2004). The Dialogue (D) represents interactivity, deep or regular involvement, which is perceived by communication between actors (Prahalad and Ramaswamy 2004) and is thus dependent on the existence of communication, which is based on channels that allow not only the exchange of information 
Table 1 DART elements

\begin{tabular}{ll}
\hline DART elements & Explanation of the term found in the literature review \\
\hline $\begin{array}{l}\text { Dialogue } \\
\text { Access }\end{array}$ & $\begin{array}{l}\text { It is interactivity; empathetic understanding; it is much more than listening } \\
\text { Customers want access to experiences. There is not just the "owing asset". Ex: } \\
\text { drinking an export type coffee in a supermarket. There is a whole environment } \\
\text { that can provide a unique experience, such as background music, different } \\
\text { dishes, aroma, friendliness of the attendant, etc. }\end{array}$ \\
(Risk management) & $\begin{array}{l}\text { It concerns the probability of omitting information that may negatively affect the } \\
\text { consumer. Customers know more about the products than they used to, so they } \\
\text { can assess and manage risks themselves }\end{array}$ \\
Transparency & $\begin{array}{l}\text { Information is more readily available and accessible. Transparency implies } \\
\text { information sharing }\end{array}$ \\
\hline
\end{tabular}

but also the exchange of ideas (Prahalad and Ramaswamy 2004). Access (A) is the search for the consumer/beneficiary for information and the experience itself, Risk Management or Sharing (R) is the probability of damage or omission of information to the consumer, and, finally, Transparency $(\mathrm{T})$, which refers to the organizational relevant information given to the consumer. Without these elements, there is no possibility and factuality of co-creating value between actors (Prahalad and Ramaswamy 2004).

At this moment of the text, value and value co-creation have been introduced; it is pertinent to present the new market logic stream for the term "value".

Through logical reasoning and without empirical confirmation, SDL brought a new perspective on the co-creation of value, construction, and perception. Vargo and Lusch (2004) directed the nature of their discussions to knowledge and other operant resources as sources of value. Vargo and Lusch (2004) introduced the concept of "service" in their seminal theoretical work, arguing that the service should lead to the co-creation of value. Furthermore, they meant "competencies", or using one's knowledge or talent to benefit others by service. In this concept, the relationship moved from transactional to relational, with actors (customers, clients, partners, and society) interacting to co-create value rather than carrying out exchange transactions (Prahalad and Ramaswamy 2004).

SDL has been refined and expanded since its seminal article in 2004. The premises were summarized in five essential axioms in a recent essay by Vargo (2018), as shown in Table 2.

These axioms reveal the essential premises conveyed in 2004 (Vargo and Lusch 2016).

\section{Understanding value proposition in non-profits}

According to Fifield and Seligman (2009), the value proposition and value perception are complex equations composed of subjective elements such as benefits, price (expensive or cheap), and emotions. However, some writers have reservations regarding the term "value" and its variants (proposition, perception, and co-creation). They claim that there has been little scholarly effort and dedication to truly 


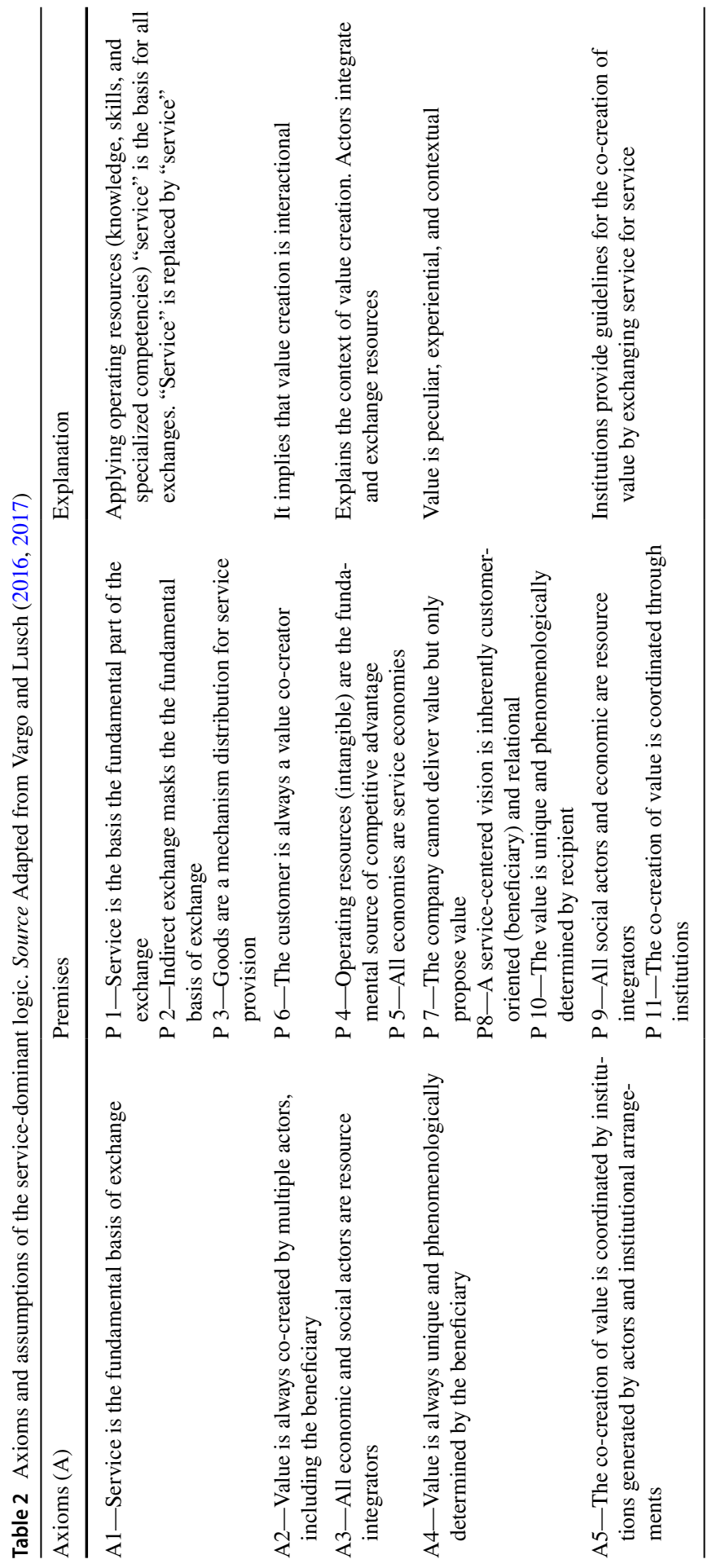


understanding what it means to create, provide, or co-create value (Fifield and Seligman 2009).

The literature emphasizes the importance of obtaining a better knowledge about value phenomena in general and, more specifically, the value proposition in the context of non-profits (Lopes and Alves 2020) and the SDL (Vargo and Lusch 2017; Loos et al. 2019). In exploratory readings on value co-creation, Maier et al. (2016) said that when examining the theme in NPOs (or any other organizational type), the organization fundamentally emerges as a value proposer, and the individual is the beneficiary and co-creator of this proposed value (i.e., Van Puyvelde 2016; Cabral et al. 2019). However, in a donor $x$ NPO relationship, the value proposed in the system benefits the organization. The current study completes a cycle in which the NPO provides value to the system; the system identifies, complements, and/or enhances the proposed value, and the value is thus returned to the NPO, which is also the beneficiary of the proposed value. NPO not only proposes value through the assistance provided, but it also benefits from the exchanged value. The NPO provides value to society by providing its services, and if the recipient is satisfied, the NPO is successful. If the beneficiary (the person who receives the service) thinks it is good, it can lead to word-of-mouth endorsements (Spena et al. 2012), donations (Austin and Seitanidi 2012), innovation (Vargo and Lusch 2016), or financial and social sustainability (Jenner and Fleischman 2017). At this point, the NPO becomes a beneficiary of the value co-created when the resource is received (donation).

\section{Methodology}

This section explains the methodological process for developing this research in detail. Any exploratory research aims to gather data and detect patterns, ideas, insights, commonalities, contradictions, and so forth (Yin 2011, 2015), which add to understanding more complex phenomena (Gummesson 2001; Yin 2015). As value is always determined uniquely and phenomenological by the beneficiary (Vargo et al. 2008), it makes sense to use this exploratory, investigative step. According to Vargo et al. (2008), phenomenologically is based on context and time. The methodological approach used in this research is qualitative and deductive. We chose to carry out qualitative research, as the idea is not a statistical generalization of the research findings but specific contributions to the analyzed cases (Yin 2015). According to Stake (1995), it is feasible to obtain a natural generalization in qualitative research, where the researcher must describe the complete methodological path in detail.

In terms of the number of case studies required for any investigation, scholars claim that there is no predetermined number of cases that must be assessed in a qualitative study as long as the researcher can respond and analyze the questions that were previously addressed (Gibbs 2014; Gummesson 2017). Therefore, cases are not relevant in qualitative studies (Gummesson 2017). For example, Eisenhardt (1989), a qualitative management expert researcher, recommends four to ten cases.

Deductive analysis was applied since the analytic categories (such as value cocreation attributes and outcomes) were pre-defined using relevant literature on value co-creation and service-dominant logic. However, it is worth noting that the 
researchers were always on the lookout for the emergence of new categories that had not been pre-defined prior to the start of the research.

The researchers conducted multiple case studies to highlight similarities and contrasts across the organizations under investigation. It is worth noting that these organizations were chosen because they influence the communities they are based on. These NPOs are essential in the region, contributing to treating children and individuals who benefit from their healthcare services. The selected NPOs were: (i) one dedicated to taking care and assisting children that have cancer, which is called NPO I; (ii) the second NPO assists, treats, and help parents and children with neurologic and/or psychiatric syndrome (autism, down syndrome): NPO II; and (iii) NPO III assists children with lung diseases. All NPOs belong to the health care system and directly treat only children. Because the donors did not wish to be identified, we named them according to the initial letters of their names, i.e., Donor "A", Donor "J" and Donor "R" donate to NPO I; donors "F", "B" and "V" donate to NPO II. Donors "L", "M" and "BB" donate to NPO III.

Pertinently to say, aspects related to the context, such as the economy, politics, and the situation of public calamity declared due to the Coronavirus, must be observed because they could influence responses, or even the willingness of the donor or NPO to give certain information, which makes this a limitation of the research. Nevertheless, considering that reality is socially constructed, social science relies on context and time (DiMaggio and Powell 1983; Vargo et al. 2008). Furthermore, this study was conducted under a catastrophic health situation, and it revealed several behaviors and explanations that would not occur in normal circumstances. Thus, at the same time, this was an opportunity to understand value co-creation and fundraising in an unusual condition.

This study was developed with primary and secondary data, and the primary data were collected through (semi-structured script) interviews with 6 managers (2 managers from each NPO) and 9 donors (3 donors from each NPO). The average duration of the interviews was $50 \mathrm{~min}$ each. It is noteworthy that the interviewees' consent was requested to record and then transcribe the interviews for detailed data analysis.

Days later, after the interview step, direct observation was realized in NPOs' telemarketing/commercial department. Thus, a day was spent in the commercial/telemarketing sector of each NPO. The idea was to observe or document the organization's communication and engagement with donors and potential donors and the interaction between workers, potential donors, and frequent donors. Notes collected from the direct observation step served to/for data triangulation in the content analysis.

After the observation step, financial and marketing reports were analyzed, and the systematization of the study was initiated. The entire systematization of the qualitative approach followed, primarily, the instructions of three qualitative research experts: Kuckartz and Rädiker (2019) and Gibbs (2014). Their systematization occurs through (a) data input into the software, (b) exploration of the material through the broader coding of data, (c) definition and aggregation of the thematic unit of analysis, which in this study took place through the participant's prayer and/ or contextual analysis, (d) confirmation of the categories or codes of analysis using 
tools, such as word clouds, word frequencies, matrix analysis, lexical analysis, and, finally, (e) treatment of data and results.

Content analysis systematized each step of the analytical process. It was carried out using MAXQDA software to categorize relevant information using codes, colors, and/or symbols. MAXQDA is a Computer Assisted Qualitative Data Analysis (CAQDAS) Software.

Following this brief explanation, the findings are provided in the following section. The sequence of the presentation of the results are: (i) how NPOs propose value to society in order to raise funds; (ii) Donors' and NPOs' Opinions about Donation and Value Co-creation, and (iii) Requirements for value co-creation to take place in this donation context.

\section{Results and discussion}

\section{NPOS' value proposition to society}

According to the research, NPOs propose value to the environment as a whole; that is, the value proposition is typically emphasized in their mission, which is why the NPOs exist. Although the value proposition may be provided to the system, when the NPO contacts each actor (donor, patient, patient's family members, etc.), such as during an event or a phone call, the NPO directs the value proposition based on the circumstances. For example, they cite the reduction of funds received due to the Covid-19 pandemic and the need for (financial) support to save lives.

Many actors and indirect beneficiaries perceive value in the process, such as health professionals who frequently work as volunteers while also sharing their talents with private companies that want to be partners of these NPOs. This society knows the NPO is offering (satisfactory) service, or just general donors of time, treasure $(\$)$, or talent (TTT-Donor).

NPOs also propose value by publicizing their cause and accomplishments on the internet. Concerning social media, NPOs' managers said that users who follow the NPO on the social network platform are generally donors or supporters of their cause or people that have identified value in their proposition. In addition, online users are often ex-patients or relatives of these patients, who, after experiencing the disease, end up disclosing NPOs' social cause, especially if the treatment result was positive.

It should be noted that the NPO board of directors has a significant effect on community fundraising. This implies that the qualifications and reputation of the NPO's employees will be leveraged as a value proposition to the community.

The president of one of the NPOs is a member of the city's high society, the wife of a regional businessman, and a wine industry businesswoman. So her access to corporations and wealthy individuals is facilitated; nevertheless, others expect benefits from such a "relationship", including being recognized for their donations or receiving discounts on the wines her company sells.

NPO III states: "Our value proposition is based on humanization and emotions. In the awareness that we are all collectively responsible for one another. We have 
good professionals, some money, the know-how, and the goodwill to change children's lives".

NPO I and NPO II similarly propose value (focusing on the patient and the excellent structure (professionals, know-how, capacity, reputation). However, NPO III directs their efforts to demonstrate that they care for the family as a whole, not just the child or patient and that the family's benefits are in terms of health and social stability, and development.

The whole family is problematic, not just the child with the disease. They are usually unstructured, particularly emotionally... [We show that not only the child has the right to continuous medication, but the mother can care. There are professionals to hear her, to medicate her, to qualify her, to "just be there"].

Thus, it can be noted that the NPOS value proposition for society aims to cover a large part of the stakeholders involved with the organizations. The goal is to add value to everyone involved. However, it is noted that the NPOS has difficulties reaching some specific audiences. It is usually possible to reach the older partners who already know the defended cause or the ex-users who took advantage of the services offered by the NPOS. Attracting new partners (private companies) and receiving government assistance is more difficult for NPOS due to the turnover of managers in public administration.

\section{Donors' and NPOs' opinions about donation and value co-creation}

Randall et al. (2011) and Yi and Gong (2013) summarise value co-creation as a multidimensional concept whose main dimensions include dialogue, connection, and commitment.

For Donor "R", value co-creation is a goal, an objective, something to be achieved: "Value co-creation is an objective that will engender concrete results, as long as it is collaborative".

Another respondent defines it as coming together, becoming a part of a sum that would bring people out of terrible misery and, in the end, make people feel joy and satisfaction. Donor A says:

If everyone thought this way, about the importance to help the other, the little thing done would be a lot in the end. The people involved will generate this greater whole, offering joy and satisfaction to everyone. Co-creation means adding value to the entire chain because it makes people socially aware. When a person is in need (due to an illness), I imagine that he/she feels unprotected helpless... The co-creation in this whole process is a huge emotion that comes from seeing and getting the Work done.

I am convinced that the amount I monthly donation will be added to others, which end up changing a family's life.

For donor M, only when the family assisted is healthy, economically, and psychologically stable is she sees the absolute value co-creation process. Consequently, being involved in exchanging resources is not enough for her. Only when the 
result of everything is positive, when the process results in social benefits, does it is when she believes it is over. Donor M exemplifies donation as experiences that awaken fraternal connection reduction of marginality.

From a management perspective, value co-creation is close to the cause itself. Therefore, there is almost an invitation, an opportunity for the donor to participate in this social action:

... you know, the NPO offers an opportunity, I think it is nice to talk about it. Sometimes we have several negative filters, you know [changes to a pejorative tone] "Ah, you are asking me for money ..." - no! We are offering you the opportunity to help join our cause; this is a great opportunity! Do you know what I mean? I think that this is value co-creation: getting together, taking this opportunity to participate and save children's lives; this is our cause! NPO I

A narrative of resource integration can be observed that engenders results such as cure, saving a life, and accomplishing NPO's mission. This resource integration includes time and financial resources and the NPO team's competencies, and the patient's treatment itself. This is the value proposition for donors, as noted by NPO I:

The main secret of the good results that we obtain (he particularly emphasizes donations) is that we humanize sales approaches. Of course, I am not selling or purchasing anything, but I am using various techniques to sensitize this donor. As a result, one of our methods is to avoid addressing pricing and money in favor of emphasizing values. We talk about human beings, volunteers, the relevance of our scientific work to find cures or produce treatments... Moreover, with just a few hours, or money donation of 20, 25 individuals may assist us to save a life, support those in need, or help those who are suffering. So, it is in this sense that we work and propose value.

Value is created via collaboration among all players involved in achieving the NPO's objectives. However, this achievement is only possible if the beneficiary perceives value. Therefore, according to Vargo et al. (2008), organizations cannot create value but can only propose it, as stated in Premise 7, and this value is determined by the beneficiary, as stated in Premise 10.

During the observation phase, it was possible to notice that NPO II was focused on convincing its partners (private companies) that joining a partnership and being active with the NPO would benefit them. Therefore, emphasis was placed on the (good) reputation private corporations may be associated with by supporting an NPO. Consequently, the community would have a favorable opinion of these private companies. It is as though they demonstrate their concern for money, dividends, and social issues.

From what has been investigated, it can be said that the co-creation of value occurs through interaction and the occurrence of value-adding activities that are perceived by some actors of the process, such as the beneficiary of the donation service, the donor-as an aggregator of value and resource (money), and the 
NPO, whose co-creation happens through the donor's engagement to fulfill its social objective. In this sense, not only does the NPO propose a value, but it is also the beneficiary of this proposed value in a donor and NPO relationship.

Thus, it is worth noting that subjective elements influence the perception of value co-creation for donors and organizations. This implies that it is not enough to donate money; the money must be used wisely to positively impact the lives of individuals who benefit from NPOS's services. Donors emphasize subjective elements such as a child's smile, a family hugging each other, and other sentimental issues. Furthermore, the value is tied to the accomplishment of the NPO's mission; that is, the value is related to the opportunity of changing the lives of the beneficiaries, even if only for a short time.

\section{Identification of the elements necessary for value co-creation to take place in this donation context}

This section provides insight into the requirements that non-profits must fulfill to draw funders' attention to their cause. It also discusses why donors choose to exchange resources with the NPO.

Each respondent highlighted particular traits required for the value co-creation process. For donors, some of these traits are innate or developed qualities of a person, while others are NPO's required attributes. All of these factors influence the circumstances for value co-creation in this context.

The variables identified by the direct observation or added by the participants in the interviews were essential integrators of the value co-creation process, which can be considered requirements for this process. The acronym presents them: SPEBSeriousness, Personality, Empathy, and Background. So far, they have not been discussed in the literature.

\section{(S)eriousness of the work}

Seriousness in work carried out by the NPO favors engagement and partnership. Donor BB.

....Also, there is the matter of trust. Donors must have faith in the organization to which they are contributing. Everyone on the board of directors and everyone else who works there must be honest. It should be self-evident that the cash donated to the NPO will be used per the organization's regulations. You cannot have complete control over everything, so you must believe that there are serious and transparent people getting the job done. Donor L.

An Organization should undertake real effort in order for value co-creation to occur. Donor A, for example, visits the NPO regularly. He also reads the annual reports, follows the NPO on social media, and exchanges ideas and information with other donors.

Some antecedents of value co-creation have previously been recognized in the strategic marketing literature, such as loyalty, cooperation, engagement, and leadership (Neghina et al. 2015; Zhang and Chen 2008; Leclercq et al. 2016). These 
elements, however, are inherent in the individual (or his activity), an individual characteristic that facilitates the process of value co-creation. On the other hand, seriousness is related to the NPO's name or brand and the work it undertakes. It comes from the outside to the inside; it is a trait of the organization, not of the person. Consequently, the value proposition does not matter in this situation because if the donor has heard negative rumors about the NPO, it does not get the chance to propose anything. To our knowledge, this organizational element-the seriousness of the work developed by the NPO-has not appeared as a predecessor of value cocreation in the literature.

(P)ersonality From the Greek Persona, mask, which represents a person's style of interacting with the world, the individual in his relationship with the world. It is frequently described in terms of an individual's most prominent traits due to genetics, experiences, and the environment (Nicholson 2003; Westjohn et al. 2012). In this way, Donor J declares: “The person's personality or even his/her life experiences are components that enhance value co-creation".

She explained that if a person is aware of what is happening around him or her and is sensitive to social concerns, this should inspire the co-creation of something much more meaningful to society. Another donor adds: "Some personal characteristics indicate some behaviors. Some actions are already expected, understand?" (Donor L). She claims that inspiring people end up influencing others:

If I come here overjoyed to tell you that I support a non-profit organization and that it brings me tremendous joy, and that today I went there, that I spent time, money, and attention, and that "it made my day", this enthralls others. Excitement is contagious, and I believe it drives others to push themselves outside their comfort zone.

Besides, Donor M complements:

...Some people have a social profile because they constantly want to assist others - this is a personal trait, you know - they always want to help others.

Donor $\mathrm{M}$ is not particularly referring to the third sector. She says that some people help for personal interests, while others help because they feel compelled to do so; they sense a call.

(E)mpathy According to the participants, empathy is required for value co-creation to take place:

We have never conducted a donor survey, you know, such a survey could be interesting: why are you financially helping, right? I cannot be sure, but many people have some biases. So, I think that it is being empathic: either you have been through the situation, or you put yourself in the person's shoes, and this engages you. NPO I

There are individuals who walk by a homeless man and do not see him, or who walk by a child on the street and do not notice him; in this regard, there are people who do not care about this. Many individuals say "no, I am not donat- 
ing" claiming that it is a state obligation, that they already pay many taxes, and that they will not spend any more money because it is not their responsibility. Donor L

NPO II's manager says that empathy is:

...something you learn; it is something given by example. My father had always been rigorous and demanding about our attitude towards the disabled. He was a role model and had always said, it can happen to your family in the future; it can be your son.

The literature has ignored empathy as a required element of value co-creation. However, finding it in this donation context makes sense, as the donor's empathy towards the disease can sensitize him/her and instigate their interaction with the NPO, which turns into engagement through greater participation in the value chain.

\section{Background}

Perhaps it would have been more difficult to become involved with social problems if my parents had not provided me with a basic education (in values) and made me aware of the financial difficulties we were experiencing, perhaps it would be more difficult to get involved with social problems. Donor A.

Both Personality and Background are centered on child-rearing, whereby citizenship is shaped. Yi and Gong (2013) have already mentioned that value co-creation involves citizenship behaviors developed since childhood. Citizenship behaviors (including volunteering) demonstrate that the person is committed to a better society. This refers to the third characteristic related to the process of co-creating value identified by Transformational collaborations, according to Austin and Seitanidi (2012), which go beyond the previous two stages, which are more transactional (related to exchange and eventual relationship). Transformational is a higher degree of convergence since it aims to co-create significant societal changes. Donors and non-profit organizations pool their resources and ideas to build social networks that promote social progress. This partnership implies a value co-creation experience: "The person, as a transformative force in society, and the corporation, as a socially responsible entity, must continue to complete the task. So, do you understand? We help donors in feeling more (emphasis on the word "more") responsible for social change." NPO I.

It can be noted that some elements are essential for the existence of the co-creation of value between NPOs and donors. First, transparency of activities is a significant concern. This was emphasized as crucial because it includes means of mobilization to raise resources, decision-making, strategy planning, and management reporting, to name a few essential items. Transparency is critical, given that NPOS uses third-party resources and has a significant local influence on development in the region in which they operate.

Another element pointed out as necessary for value co-creation is the importance of the cause being defended; by the NPO; as previously stated, emotional issues 
influence value co-creation. Some donors sympathize with the social cause. Furthermore, some donors associate the donation with personal struggles, recalling a needy relative, a neighbor who once needed assistance, etc. As a result, it is worth noting that both objective and subjective factors are involved in the co-creation of value.

\section{Conclusions}

Service-Dominated Logic consists of an alternative perspective to understand the world of social and economic exchanges between human actors by focusing on relational exchanges. Through it, this study explored the value of co-creation processes in a donation context and broad the empirical knowledge on the subject. According to the findings, non-profits employ marketing techniques to propose a value, mainly via humanizing "sales techniques" and promoting their work on the internet (social media). Moreover, most donors perceive value co-creation as a positive collaborative action. Each stage inside the value creation process comprises an adding value (chain), and the donor perceives himself/herself as a component in this chain. There is no donation if the donor does not perceive value in the NPO's value proposition. As a result, the beneficiary's perspective and judgment of value are influenced by some value aggregators (actors), including governments that must direct funds to the third sector, the community, and the donors themselves. NPOs understand that value co-creation is necessary to reach their social objective.

An intriguing aspect of this research was the perceived behavior of the participants and those observed in the telemarketing sector. A favorable environment for value co-creation was identified because it is full of shared stories, interests, and similar mindsets. Additionally, there is a strong social awareness and commitment to carry out social transformations, mentioned in the literature by Austin and Seitanidi (2012).

Theoretical and empirical contributions are presented in this study. Firstly, it goes beyond the conceptual and literature review discussions that represent the vast majority of SDL's contribution to the strategic management literature (Vargo and Lusch 2017). This study might help managers make strategic marketing decisions and improve their understanding of how value co-creation can assist non-profits in raising funds.

Finally, the findings of this study cannot be generalized to other situations. This is one of the study's most significant limitations, which arises from the study's limited sample (15 interviews). However, the study may be deemed valid and applicable to the organizations included in the research and perhaps other NPOs with comparable features. Aside from that, the methodology was detailed enough to be replicated. By supporting ethical research, our study has struck a balance between the interests of academia and practitioners.

Acknowledgements We would like to thank the Non-Profits and donors for participating in this project.

Author contributions Prof. Dr. Researcher RK idealized the project and carried out the qualitative research. She wrote the central part of the manuscript and replied to the reviewers. Prof. Researcher MCVdeO checked through the methodology section assisted with the research's results. 
Funding The authors declare that the authors did not receive support from any organization for the submitted Work; No funding was received to assist with the preparation of this manuscript; No funding was received for conducting this study.

Data availability The actual data and analysis are available upon request.

\section{Declarations}

Conflict of interest On behalf of all authors, the corresponding author states that there is no conflict of interest.

Informed consent Formal consent was obtained from all participants for being included in this study.

\section{References}

Austin JE, Seitanidi MM (2012) Collaborative value creation: a review of partnering between non-profits and businesses: part I. Value creation spectrum and collaboration stages. Non-Profit Volunt Sector Q 41(5):726-758. https://doi.org/10.1177/0899764010380927

Avner MA (2016) Advocacy, lobbying, and social change. In: Renz DO, Herman RD (eds) Handbook of non-profit leadership and management, 3rd edn. The Jossey-Bass, San Francisco, pp 396-426

Cabral S, Mahoney JT, McGahan AM et al (2019) Value creation and value appropriation in public and non-profit organizations. Strateg Manage J40(4):465-475. https://doi.org/10.1057/9781137294678. 0655

DiMaggio P, Powell W (1983) The iron case was revisited institutional isomorphism and collective rationality in organizational field. Am Sociol Rev. https://doi.org/10.1177/0003122421996686

Eisenhardt KM (1989) Building theories from case study research. Acad Manage Rev 14(4):532-550

Fifield P (2009) Strategic marketing decisions module: lecture presentation. University of Southampton, Southampton

Fifield P, Seligman J (2009) Delivering the value proposition module: lecture presentation. University of Southampton, Southampton. Instituto Brasileiro de Geografia e Estatística

Gibbs GR (2014) Using software in qualitative analysis. In: Flick U (ed) The SAGE handbook of qualitative data analysis. SAGE Publications, London, pp 277-294

Gummesson E (2001) Are current research approaches in marketing leading us astray? Mark Theory 1(1):27-48. https://doi.org/10.1177/147059310100100102

Gummesson E (2017) Case theory in business and management: reinventing case study research. SAGE Publications, London

IBGE (2015) Estatística. In: Instituto Brasileiro de Geografia e Estatística. Acessível via IBGE. https:// ww2.ibge.gov.br/home/estatistica/economia/peas/2014_2015/default.shtm. Accessed 20 July 2019

IFG (2020) Coronavirus and unemployment: the importance of government policy: a five nation comparison. In: Institute for Government. Insight. https:/www.instituteforgovernment.org.uk/sites/defau lt/files/publications/coronavirus-unemployment-five-nation-comparison.pdf. Accessed 10 July 2020

Jenner P, Fleischman D (2017) Enhancing social enterprise sustainability: a value co-creation pathway. J Soc Behav Res Bus 8(1):57-74

Joas H (2001) The gift of life: the sociology of religion in Talcott parsons' late work. J Class Sociol 1(1):127-141. https://doi.org/10.1177/14687950122232477

Kluckhohn C (1951) Values and value-orientations in the theory of action: an exploration in definition and classification. Harvard University Press, Cambridge

Kuckartz U, Rädiker S (2019) Analysing qualitative data with MAXQDA. Springer, Birkhäuser

Leclercq T, Hammedi W, Poncin I (2016) Ten years of value cocreation: an integrative review. Rech Appl Mark (English Edition) 31(3):26-60

Loos CP, Carvalho KV, Teixeira RV (2019) O Campo de Estudos em Lógica Dominada pelo Serviço: uma Análise Bibliométrica. Rev FSA 16(4):20-36. https://doi.org/10.12819/2019.16.4.2 
Lopes TSA, Alves H (2020) Coproduction and co-creation in public care services: a systematic review. Int J Public Sect Manage 33(5):561-578. https://doi.org/10.1108/IJPSM-10-2019-0259

Maier F, Meyer M, Steinbereithner M (2016) Non-profit organizations becoming business-like: a systematic review. Non-Profit Volunt Sector Q 45(1):64-86. https://doi.org/10.1177/0899764014561796

McColl-Kennedy JR, Gustafsson A, Jaakkola E, Klaus P, Radnor, ZJ, Perks H, Friman M (2015) Fresh perspectives on customer experience. J Serv Mark 29(6/7):430-435. https://doi.org/10.1108/ JSM-01-2015-0054

Neghina C, Caniëls MC, Bloemer JM, van Birgelen MJ (2015) Value cocreation in service interactions: dimensions and antecedents. Mark Theory 15(2):221-242

Nicholson IA (2003) Inventing personality: Gordon Allport and the science of selfhood. American Psychological Association

Osei-Frimpong K, Owusu-Frimpong N (2017) Value co-creation in health care: a phenomenological examination of the doctor-patient encounter. J Non-Profit Public Sector Mark 29(4):365-384. https://doi.org/10.1080/10495142.2017.1326356

Payne AF, Storbacka K, Frow P (2008) Managing the co-creation of value. J Acad Mark Sci 36(1):83-96. https://doi.org/10.1007/s11747-007-0070-0

Prahalad CK, Ramaswamy V (2004) Co-creation experiences: the next practice in value creation. J Interact Mark 18(3):5-14. https://doi.org/10.1002/dir.20015

Randall WS, Gravier MJ, Prybutok VR (2011) Connection, trust, and commitment: dimensions of cocreation? J Strateg Mark 19(01):3-24. https://doi.org/10.1080/0965254X.2010.537760

Spena TR, Caridà A, Colurcio M et al (2012) Store experience and co-creation: the case of temporary shop. Int J Retail Distrib Manage 40(1):21-40. https://doi.org/10.1108/09590551211193586

Stake RE (1995) The art of case study research. Sage, Thousand Oaks

Thome H (2015) Values, sociology. In: Wright JD (ed) International encyclopaedia of the social and behavioural sciences, 2nd edn. Elsevier, Oxford, pp 47-53

Van Puyvelde S, Caers R, Bois Du et al (2016) Managerial objectives and the governance of public and non-profit organizations. Public Manage Rev 18(2):221-237. https://doi.org/10.1080/14719037. 2014.969760

Vargo SL (2018) Service-dominant logic: backward and forward. In: The SAGE handbook of servicedominant logic. pp 720-739

Vargo SL, Lusch RF (2004) Evolving to a new dominant logic for marketing. J Mark 68(1):1-17. https:// doi.org/10.1509/jmkg.68.1.1.24036

Vargo SL, Lusch RF (2016) Institutions and axioms: an extension and update of service-dominant logic. J Acad Mark Sci 44(1):5-23. https://doi.org/10.1007/s11747-015-0456-3

Vargo SL, Lusch RF (2017) Service-dominant logic 2025. Int J Res Mark 34(1):46-67. https://doi.org/10. 1016/j.ijresmar.2016.11.001

Vargo SL, Maglio PP, Akaka MA (2008) On value and value co-creation: a service systems and service logic perspective. Eur Manage J 26(3):145-152

Westjohn SA, Singh N, Magnusson P (2012) Responsiveness to global and local consumer culture positioning: a personality and collective identity perspective. J Int Mark 20(1):58-73. https://doi.org/10. $1509 /$ jim.10.0154

Yi Y, Gong T (2013) Customer value co-creation behavior: scale development and validation. J Bus Res 66(9):1279-1284. https://doi.org/10.1016/j.jbusres.2012.02.026

Yin RK (2011) Applications of case study research. Sage Publications, London

Yin RK (2015) Qualitative research from start to finish. Guilford Publications, New York

Zhang X, Chen R (2008) Examining the mechanism of the value co-creation with customers. Int J Prod Econ 116(2):242-250 